\title{
Preliminary Clinical Experience with the Bryan Cervical Disc Prosthesis
}

Jan Goffin, M.D., Ph.D.

University Hospital, Leuven, Belgium

\section{Adrian Casey, M.D.}

National Hospital for Neurology and Neurosurgery, London, England

Pierre Kehr, M.D.

Centre de Traumatologie et d'Orthopédie, Illkirch, France

Klaus Liebig, M.D., Ph.D.

Orthopädische Abteilung des Waldkrankenhaus St. Marien, Erlangen, Germany

Bengt Lind, M.D., Ph.D.

Sahlgrenska University Hospital, Gothenberg, Sweden

Carlo Logroscino, M.D.

Università Cattolica del Sacro Cuore, Rome, Italy

\section{Vincent Pointillart, M.D.,} Ph.D.

Unité de Pathologie RachidienneC.H.U. Pellegrin, Bordeaux, France

\section{Frank Van Calenbergh,}

M.D.

University Hospital, Leuven, Belgium

Johannes van Loon, M.D.

University Hospital, Leuven, Belgium

\section{Reprint requests:}

Jan Goffin, M.D., Ph.D., Department of Neurosurgery, University Hospital Gasthuisberg, Herestraat 49, B-3000 Leuven, Belgium.

Email: jan.goffin@uz.kuleuven.ac.be

Received, March 5, 2002.

Accepted, May 29, 2002.
OBJECTIVE: The concept of accelerated degeneration of adjacent disc levels as a consequence of increased stress caused by interbody fusion of the cervical spine has been widely postulated. Therefore, reconstruction of a failed intervertebral disc with a functional disc prosthesis should offer the same benefits as fusion while simultaneously providing motion and thereby protecting the adjacent level discs from the abnormal stresses associated with fusion. This study was designed to determine whether a new, functional intervertebral cervical disc prosthesis can provide relief from objective neurological symptoms and signs, improve the patient's ability to perform activities of daily living, decrease pain, and provide stability and normal range of motion.

METHODS: We conducted a prospective, concurrently enrolled, multicenter trial of the Bryan Cervical Disc Prosthesis (Spinal Dynamics Corp., Mercer Island, WA) for the treatment of patients with single-level degenerative disc disease of the cervical spine. Patients with symptomatic cervical radiculopathy and/or myelopathy underwent implantation with the Bryan prosthesis after a standard anterior cervical discectomy. At scheduled follow-up periods, the effectiveness of the device was characterized by evaluating each patient's pain, neurological function, and range of motion at the implanted level.

RESULTS: Analysis included data regarding 60 patients at 6 months with 30 of those patients at 1 year. Clinical success at 6 months and 1 year after implantation was 86 and $90 \%$, respectively, exceeding the study's acceptance criteria of $85 \%$. These results compare favorably with the short-term clinical outcomes associated with anterior cervical discectomy and fusion reported in the literature. At 1 year, there was no measurable subsidence of the devices (based on a measurement detection threshold of $2 \mathrm{~mm}$ ). Evidence of anterior and/or posterior device migration was detected in one patient and suspected in a second patient. There was no evidence of spondylotic bridging at the implanted disc space. The measured range of motion in flexionextension, as determined by an independent radiologist, ranged from 1 to 21 degrees (mean range of motion, $9 \pm 5$ degrees). No devices have been explanted or surgically revised.

CONCLUSION: Discectomy and implantation of the device alleviates neurological symptoms and signs similar to anterior cervical discectomy and fusion. Radiographic evidence supports normal range of motion. The procedure is safe and the patients recover quickly. Restrictive postoperative management is not necessary. However, only after long-term follow-up of at least 5 years will it become clear whether the device remains functional, thus confirming these early favorable results. In addition, the influence on adjacent motion segments can be assessed after at least 5 years of follow-up.

KEY WORDS: Cervical vertebrae, Degenerative disc disease, Herniated disc, Intervertebral disc, Joint prosthesis implantation, Spinal fusion, Spondylosis 
$\mathbf{T}$ he concept that interbody fusion of the cervical spine leads to accelerated degeneration of adjacent disc levels due to increased stress from the fusion is widely postulated $(1,6,8,9,11,14,20,22,25)$. Therefore, reconstruction of a failed intervertebral disc with a functional disc prosthesis should offer the same benefits as fusion while providing motion, thereby protecting the adjacent level discs from the abnormal stresses associated with fusion. The purpose of this study is to determine whether a new functional intervertebral cervical disc prosthesis, when accurately implanted, can provide relief from objective neurological symptoms and signs, improve the ability of the patient to perform activities of daily living, decrease pain, and provide stability and normal range of motion. This report describes the first 20 months of the study.

\section{PATIENTS AND METHODS}

\section{Device Description}

The Bryan Cervical Disc Prosthesis (Spinal Dynamics Corp. Mercer Island, WA) is a cervical intervertebral disc prosthesis designed to permit motion similar to the normal cervical functional spinal unit. The prosthesis is intended to treat stable cervical degenerative disc disease without fusion, thereby providing the patient with the capability for motion at the treated level. The device (Fig. 1) consists of a polyurethane nucleus designed to fit between two titanium alloy surfaces (shells). The bone-contacting surface of each shell includes a titanium porous coating to encourage bony ingrowth and long-term stability. A polyurethane sheath surrounds the nucleus and is attached to the shells with titanium wire, forming a closed compartment. Titanium alloy seal plugs provide for retention of a sterile saline lubricant. Anterior stops on each shell help to prevent posterior migration of the device, and the presence of a hole in these stops facilitates insertion of the device with a specialized instrument. The prosthesis is presently designed in five diameters: 14 , $15,16,17$, and $18 \mathrm{~mm}$.

\section{Study Design}

Patients were concurrently enrolled in a multicenter evaluation of the prosthesis

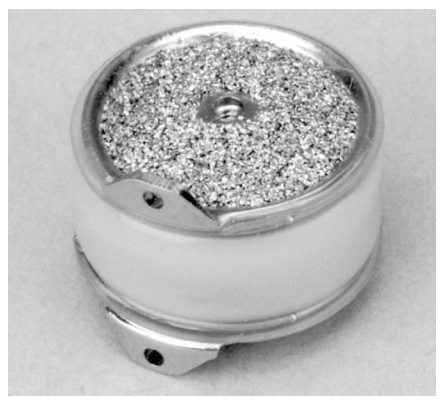

FIGURE 1. The Bryan Cervical Disc Prosthesis (Spinal Dynamics Corp., Mercer Island, WA).

level degenerative disc disease of the cervical spine. The prospective study was approved by the ethics committee and, as required, the regulatory agencies for each center. Patient inclusion criteria included disc herniation or spondylosis, with radiculopathy and/or myelopathy, which had not responded to conservative treatment. Exclusion criteria included previous cervical spine surgery involving any other device, axial neck pain as the solitary symptom, significant cervical anatomic deformity or clinical instability, and active infection.

Patient assessments are conducted in accordance with the schedule outlined in Table 1. The primary endpoint is classification based on relief of preoperative symptoms (as assessed by the patient using the Cervical Spine Research Society and SF-36 patient questionnaires) and relief of objective neurological signs (as assessed by the physician conducting a neurological examination) associated with the treated level. For the C4 dermatome, the top of the arm and shoulder was examined, and for the C5 dermatome, the lateral proximal part of

TABLE 1. Scheduled assessments

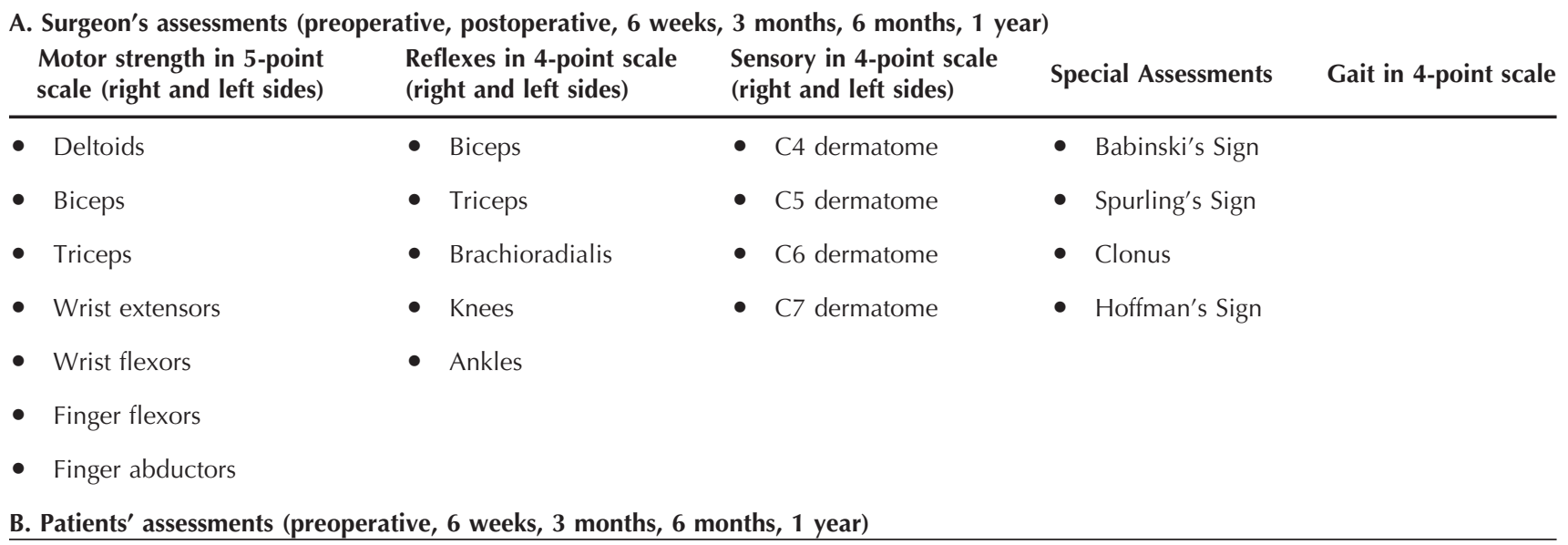

Neck pain severity in 6-point Arm pain severity in 6-point scale scale
Ability to function at activities of daily living in 4-point scale 


\section{Goffin ET AL.}

the arm was examined. Data were entered into a database, and, in accordance with a scoring algorithm, assessments were averaged to determine relief of neurological symptoms and signs. Results were scored according to modified Odom's criteria and categorized as follows:

Excellent: Improvement in most (at least 80\%) of the preoperative signs and symptoms, with little deterioration (not more than $10 \%$ )

Good: Improvement in some (at least 70\%) of the preoperative signs and symptoms, with some deterioration (not more than $15 \%$ )

Fair: Improvement in half (at least 50\%) of the preoperative signs and symptoms, with some deterioration (not more than $20 \%$ )

Poor: Improvement in few (less than 50\%) of the preoperative signs and symptoms, or significant deterioration (more than $20 \%$ )

A literature review of anterior cervical discectomy and fusion was conducted to establish an anticipated success rate for the study $(2-4,7,8,10,12,15-19,21,23,24)$. Statistical analysis was performed on data reported in relevant articles, which established a success (excellent, good, or fair) rate of $73 \%$. On the basis of this analysis, a success rate of $85 \%$ was set as the acceptance criteria for the study. An independent radiologist analyzed the radiographs to determine range of motion and assess device migration and/or subsidence.

\section{Study Enrollment}

Devices have been implanted in 97 patients. In all cases, neural compression was verified by performing computed tomography or magnetic resonance imaging and a neurological assessment. Complete preoperative clinical and radiographic data are available for 97 patients. Sixty of the patients have been followed for 6 months; 30 of those patients have been followed for 1 year. Table 2 details the demographic variables of the patients.

\section{Operative Technique}

After discectomy, a simple gravitational referencing system is used to establish the center of the disc space. The desired location is found by locating a line containing a predetermined point within the surgical site using a series of levels and plumb lines and internal anatomic features of the surgical site. With the knowledge of the location of the center of the disc space, a milling fixture is positioned appropriately, and affixed to the vertebral bodies with bone anchors. The milling fixture precisely controls the powered cutting instruments that prepare the vertebral endplates for placement of the prosthesis. The milled vertebral endplates exactly match the geometry of the implant's convex outer surface, capturing the rim of each shell inside a ridge of bone. This tight fit provides immediate anteroposterior and lateral stability (Fig. 2).

\section{Operative Time}

Operative times for implanting the Bryan prosthesis (recorded as skin to skin) are reported in Table 3 after subtracting the first two operations for each investigator to account for the surgeon's training. In Table 3, all reported operative times for the procedures are averaged to within 1 standard deviation. The times for anterior cervical discectomy with fusion autograft, modified cage with plate (TSM: titanium surgical mesh), and approved cage (BAK-C), as described by Castro et al. (5) and Hacker et al. (13) are included for comparison.

TABLE 2. Patient demographics $(n=97)^{a}$

\begin{tabular}{|c|c|c|c|c|c|c|}
\hline Age range (yr) & \multicolumn{3}{|c|}{$26-79$} & & & \\
\hline Patient sex & \multicolumn{3}{|c|}{$\begin{array}{c}\text { Male } \\
(\mathrm{n}=41)\end{array}$} & \multicolumn{3}{|c|}{$\begin{array}{l}\text { Female } \\
(\mathrm{n}=56)\end{array}$} \\
\hline Clinical diagnosis & \multicolumn{3}{|c|}{$\begin{array}{l}\text { Radiculopathy } \\
\quad(\mathrm{n}=90)\end{array}$} & \multicolumn{3}{|c|}{$\begin{array}{l}\text { Myelopathy } \\
(\mathrm{n}=13)\end{array}$} \\
\hline Primary cause & \multicolumn{3}{|c|}{$\begin{array}{l}\text { Herniation } \\
(\mathrm{n}=75)\end{array}$} & \multicolumn{3}{|c|}{$\begin{array}{l}\text { Spondylosis } \\
\quad(\mathrm{n}=33)\end{array}$} \\
\hline Duration of symptoms & $\begin{array}{c}6 \mathrm{wk} \\
(\mathrm{n}=6)\end{array}$ & $\begin{array}{c}3 \text { mo } \\
(n=18)\end{array}$ & $\begin{array}{c}6 \text { mo } \\
(n=24)\end{array}$ & $\begin{array}{c}1 \mathrm{yr} \\
(\mathrm{n}=15)\end{array}$ & $\begin{array}{c}2 \mathrm{yr} \\
(\mathrm{n}=14)\end{array}$ & $\begin{array}{c}>2 y r \\
(n=20)\end{array}$ \\
\hline Levels implanted & $\begin{array}{l}\text { C3-C4 } \\
(\mathrm{n}=0)\end{array}$ & & & $\begin{array}{l}\text { C5-C6 } \\
(n=42)\end{array}$ & \multicolumn{2}{|c|}{$\begin{array}{l}\text { C6-C7 } \\
(n=44)\end{array}$} \\
\hline $\begin{array}{l}\text { Size of implant } \\
\text { (diameter, in mm) }\end{array}$ & $\begin{array}{c}14 \\
(\mathrm{n}=22)\end{array}$ & & & $\begin{array}{c}16 \\
(\mathrm{n}=25)\end{array}$ & $\begin{array}{c}17 \\
(\mathrm{n}=20)\end{array}$ & $\begin{array}{c}18 \\
(\mathrm{n}=9)\end{array}$ \\
\hline
\end{tabular}

a Several patients presented with multiple diagnoses and/or causes. 


\section{Length of Hospital Stay}

The total number of days in the hospital from surgery to discharge for patients who underwent implantation with the Bryan prosthesis ranged from 1 day (1) to 10 (10) days. The mean postoperative hospital stay was $3.6 \pm 2.2 \mathrm{~d}$. Length of stay varies by country, in accordance with national health care standards. No restrictive postoperative management (i.e., use of a cervical collar) has been found to be necessary.

\section{RESULTS}

\section{Clinical Results}

\section{Neurological Symptoms and Signs}

Table 4 summarizes the clinical results based on relief of preoperative symptoms (as assessed by the patient) and relief of neurological signs (as assessed by the surgeon) for the 6-month and 1-year follow-up periods. At 6 months, the scores were excellent, good, or fair for 52 (86\%) of 60 of the patients.

TABLE 3. Comparison of average length of surgery (in min) ${ }^{a}$

\begin{tabular}{cccc}
$\begin{array}{c}\text { Bryan } \\
\text { prosthesis }\end{array}$ & $\begin{array}{c}\text { ACDF with } \\
\text { iliac autograft }\end{array}$ & $\begin{array}{c}\text { TSM cage with } \\
\text { plate }\end{array}$ & BAK-C \\
\hline $126 \pm 52$ & $180 \pm 14$ & $132 \pm 6$ & $92^{b}$ \\
\hline
\end{tabular}

a TSM, titanium surgical mesh; BAK-C, Spine Tech BAK-C cervical fusion cage; ACDF, anterior cervical discretomy with fusion.

${ }^{b}$ Standard deviation not published.
This result is greater than the targeted success rate of $85 \%$. Of the 60 patients scored with 6-month follow-up, 41 were classified as excellent for clinical success. An additional five were classified as good, six as fair, and five as poor. For three patients, the reported neurological results were incomplete and/or the patient responses to the patient questionnaire were incomplete. At 1 year, the scores were excellent, good, or fair for $27(90 \%)$ of 30 of the patients. (These 30 patients were also part of the group of 60 assessed at 6 months.) This result is greater than the targeted success rate of $85 \%$ excellent, good, or fair. Fifteen of the 30 patients demonstrated improvement in all preoperative abnormal findings, with no findings unchanged or deteriorated. In the remaining 15 patients, nine had one or two findings that remained unchanged from the baseline assessments, three patients had deterioration in one finding, and three patients had deterioration in more than one finding.

\section{Complications}

In one patient the wrong level was initially operated on, with a subsequent report of unresolved pain that was corrected by follow-up surgery in which a second device was implanted at the targeted level. After the second operation, temporary dysphonia occurred. An additional surgical intervention was initiated because of a patient's report, subsequent to the 3-month follow-up, of pain as a result of insufficient far lateral decompression in the first operation as well as longterm preoperative pain. A posterior foraminotomy was performed in this case without device involvement. One patient reported pain in the right shoulder, the right arm, and the sternum region approximately 6 months after surgery. A magnetic resonance imaging study ruled out any remaining neural compression. Another patient remarked on unresolved nonspecific shoulder pain on the left side. One surgical intervention at the target space occurred approximately 26 hours after surgery. A standard drainage catheter had loosened and ceased draining. Subsequently, the patient experienced pain and shortness of breath. The reoperation revealed a prevertebral hematoma, which was evacuated, after which no active

\begin{tabular}{|c|c|c|c|c|c|c|c|}
\hline Follow-up & Clinical success rate $(n)$ & Sample size & Excellent (n) & Good (n) & Fair (n) & Poor (n) & No $\operatorname{data}^{a}(n)$ \\
\hline 6 months & $86 \%(52)$ & 60 & $68 \%(41)$ & $8 \%(5)$ & $10 \%(6)$ & $8 \%(5)$ & $5 \%(3)$ \\
\hline Radiculopathy & $88 \%(47)$ & 53 & $71 \%(38)$ & $8 \%(4)$ & $9 \%(5)$ & $8 \%(4)$ & $4 \%(2)$ \\
\hline Myelopathy & $72 \%(5)$ & 7 & $44 \%(3)$ & $14 \%(1)$ & $14 \%(1)$ & $14 \%(1)$ & $14 \%(1)$ \\
\hline 1 year & $90 \%(27)$ & 30 & $80 \%(24)$ & $3 \%(1)$ & $7 \%(2)$ & $10 \%(3)$ & \\
\hline Radiculopathy & $89 \%(24)$ & 27 & $78 \%(21)$ & $4 \%(1)$ & $7 \%(2)$ & $11 \%(2)$ & \\
\hline Myelopathy & $100 \%(3)$ & 3 & $100 \%(3)$ & & & & \\
\hline
\end{tabular}

${ }^{a}$ Missed follow-up or incomplete patient and/or surgeon forms. 


\section{Goffin et AL.}

bleeding was detected. The intervention was uneventful, and the patient responded well. There have been no device failures or explantations.

\section{Radiographic Results}

Radiographic follow-up data have been obtained for 57 of 60 patients reaching 6 months and 24 of 30 patients reaching 1 year. An independent radiologist assessed all radiographs.

\section{Device Position}

Device positioning is measured in lateral radiographs at each follow-up to ensure device instability did not occur. Subsidence has not been observed in any patient. Based on the accuracy of measuring plain radiographs, a detection threshold of $2 \mathrm{~mm}$ was used, as in fusion cage studies. Evidence of anterior and/or posterior device migration was detected in one patient and suspected in a second patient; however, migration greater than $3 \mathrm{~mm}$ has not been observed in any patient.
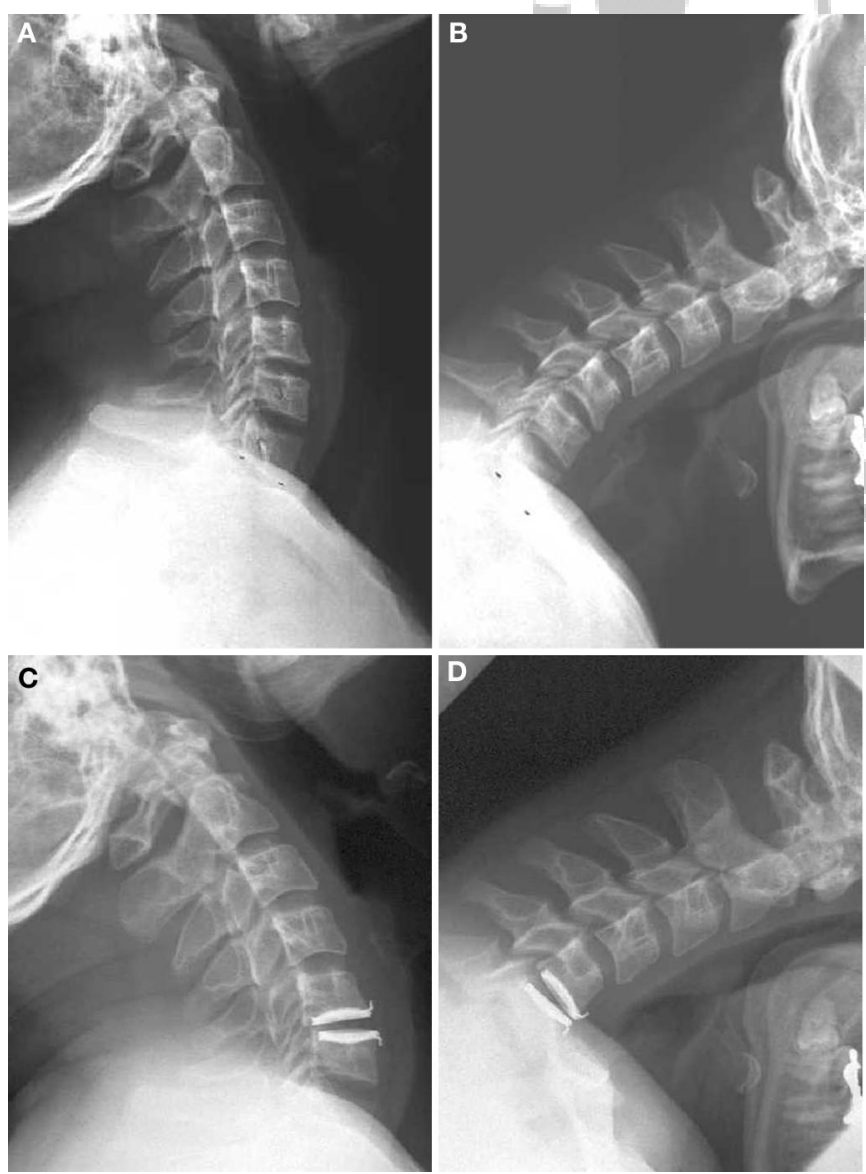

FIGURE 3. A 29-year-old man underwent implantation with a 17-mm prosthesis at C5-C6. This patient's range of motion increased by 4 degrees, from 17 degrees preoperatively to 21 degrees 12 months after surgery. $\mathrm{A}, \mathrm{B}$, preoperative range of motion $x$-rays. $\mathrm{C}, \mathrm{D}, 12$-month range of motion $x$-rays.
SF-36

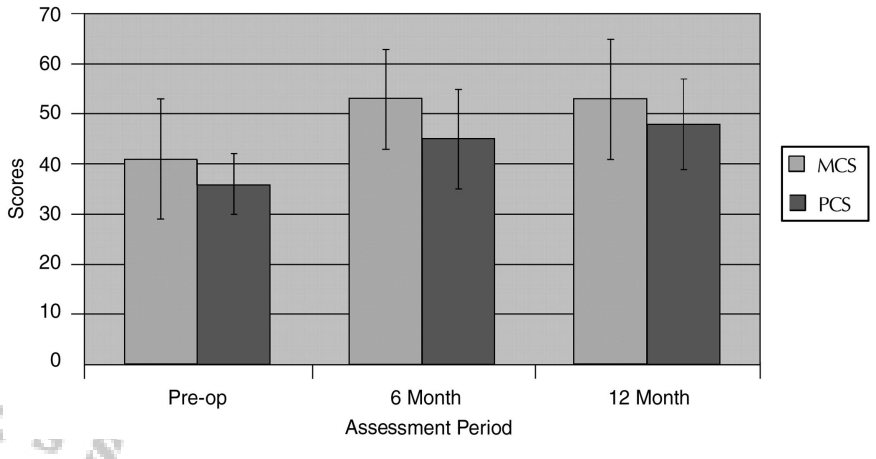

FIGURE 4. Bar graph showing the mean SF-36 summary scores ( \pm 1 standard deviation). MCS, Mental Component Summary; PCS, Physical Component Summary.

\section{Range-of-Motion Results}

Postoperative Cobb angles for flexion-extension of the functional spinal unit at the implant level, demonstrated motion of the device in flexion-extension (Fig. 3). At 6 months, 53 (93\%) of 57 patients demonstrated flexion-extension range of motion greater than or equal to 2 degrees. The remaining four patients had radiographs that were uninterpretable. Two degrees is the minimum angle that clearly establishes motion without question of measurement error due to radiographic image magnification and/or distortion as used in fusion case studies (9). The range of motion for patients at 6 months averages just less than $9 \pm 4$ degrees. Motion was observed in all patients, and there was no evidence of spondylotic bridging. At 1 year, 21 ( $88 \%$ ) of 24 patients demonstrated flexion-extension range of motion greater than or equal to 2 degrees, which is considered motion. Two patients measured 1 degree, which is considered fused; the radiograph on the remaining patient was uninterpretable. The range of motion for patients at 1 year averages just over $9 \pm 6$ degrees. There was no evidence of spondylotic bridging.

\section{Quality-of-Life Results}

The SF-36 Health Survey results are graphically illustrated in Figure 4 for the patients reaching the 1-year and 6-month follow-up examinations. Values presented for each period are the SF-36 Physical Component Summary and Mental Component Summary scores, which use U.S. population means to establish normalized scores. All Physical Component Summary and Mental Component Summary scores are normbased, with the general population mean equal to 50 and the standard deviation equal to 10 . At 12 months after implantation, patients with the Bryan prosthesis met or exceeded the U.S. population mean for Physical Component Summary and Mental Component Summary scores.

\section{CONCLUSIONS}

Twenty-seven (90\%) of 30 patients evaluated at 1-year follow-up and $52(86 \%)$ of 60 patients evaluated at 6-month 
follow-up demonstrate a clinical success rate that exceeds the anticipated success rate of $85 \%$ (Odom's classification of excellent, good, or fair). At 1 year, the Bryan prosthesis has a success rate greater than $85 \%$ with $95 \%$ confidence. The data clearly show that properly placed devices do not migrate, and that segmental motion is present. The discectomy and implantation of the device alleviates pain and improves function based on neurological signs and symptoms. Symptoms have been shown to continue improving up to the one-year follow-up period. However, only after long-term follow-up of at least 5 years will it become clear whether the device remains functional, thus confirming these early favorable results. In addition, at that future time, the influence on adjacent motion segments can be assessed.

\section{REFERENCES}

1. Baba H, Furusawa N, Imura S, Kawahara N, Tsuchiya H, Tomita K: Late radiographic findings after anterior cervical fusion for spondylotic myeloradiculopathy. Spine 18:2167-2173, 1993.

2. Bosacco DN, Berman AT, Levenberg RJ, Bosacco SJ: Surgical results in anterior cervical discectomy and fusion using a countersunk interlocking autogenous iliac bone graft. Orthopedics 15:923-925, 1992.

3. Brodke DS, Zdeblick TA: Modified Smith-Robinson procedure for anterior cervical discectomy and fusion. Spine 17[10 Suppl]:S427-S430, 1992.

4. Busch G: Anterior fusion for cervical spondylosis. J Neurol 219:117-126 1978.

5. Castro FP Jr, Holt RT, Majd M, Whitecloud TS III: A cost analysis of two anterior cervical fusion procedures. J Spinal Disord 13:511-514, 2000.

6. Cherubino P, Benazzo F, Borromeo U, Perle S: Degenerative arthritis of the adjacent spinal joints following anterior cervical spinal fusion: clinicoradiologic and statistical correlations. Ital J Orthop Traumatol 16: 533-543, 1990.

7. Chowdhary UM, Carey PC: Anterior cervical decompression and fusion for cervical degenerative disc diseases. Ir Med J 78:243-247, 1985.

8. Clements DH, O'Leary PF: Anterior cervical discectomy and fusion. Spine 15:1023-1025, 1990.

9. Döhler JR, Kahn MR, Hughes SP: Instability of the cervical spine after anterior interbody fusion: A study on its incidence and clinical significance in 21 patients. Arch Orthop Trauma Surg 104:247-250, 1985.

10. Espersen JO, Buhl M, Eriksen EF, Fode K, Klaerke A, Kroyer L, Lindeberg H, Madsen CB, Strange P, Wohlert L: Treatment of cervical disc disease using Cloward's technique: I-General results, effect of different operative methods and complications in 1,106 patients. Acta Neurochir (Wien) 70:97-114, 1984.

11. Goffin J, van Loon J, Van Calenbergh F, Plets C: Long-term results after anterior cervical fusion and osteosynthetic stabilization for fractures and/or dislocations of the cervical spine. J Spinal Disord 8:499-508, 1995.

12. Gore DR, Sepic SB: Anterior cervical fusion for degenerated or protruded discs: A review of one hundred forty-six patients. Spine 9:667-671, 1984.

13. Hacker RJ, Cauthen JC, Gilbert TJ, Griffith SL: A prospective randomized multicenter clinical evaluation of an anterior cervical fusion cage. Spine 25:2646-2655, 2000.

14. Hilibrand AS, Carlson GD, Palumbo MA, Jones PK, Bohlman HH: Radiculopathy and myelopathy at segments adjacent to the site of a previous anterior cervical arthrodesis. J Bone Joint Surg Am 81A:519-528, 1999.

15. Hubach PC: A prospective study of anterior cervical spondylodesis in intervertebral disc disorders. Eur Spine J 3:209-213, 1994.

16. Jacobs B, Krueger EG, Leivy DM: Cervical spondylosis with radiculopathy: Results of anterior discectomy and interbody fusion. JAMA 211:2135-2139, 1970.

17. Kozak JA, Hanson GW, Rose JR, Trettin DM, Tullos HS: Anterior discectomy, microscopic decompression and fusion: A treatment for cervical spondylotic radiculopathy. J Spinal Disord 2:43-46, 1989.
18. Madawi AA, Powell M, Crockard HA: Biocompatible osteoconductive polymer versus iliac graft: A prospective comparative study for the evaluation of fusion pattern after anterior cervical discectomy. Spine 21:2123-2130, 1996.

19. Martins AN: Anterior cervical discectomy with and without interbody bone graft. J Neurosurg 44:290-295, 1976.

20. Matsunaga S, Kabayama S, Yamamoto T, Yone K, Sakou T, Nakanishi K: Strain on intervertebral discs after anterior cervical decompression and fusion. Spine 24:670-675, 1999.

21. Moussa AH, Nitta M, Symon L: The results of anterior cervical fusion in cervical spondylosis: Review of 125 cases. Acta Neurochir (Wien) 68:277288, 1983.

22. Pospiech J, Stolke D, Wilke HJ, Claes L: Intradiscal pressure recordings in the cervical spine. Neurosurgery 44:379-385, 1999.

23. Savolainen S, Usenius JP, Hernesniemi JA: Iliac crest versus artificial bone grafts in 250 cervical fusions. Acta Neurochir (Wien) 129:54-57, 1994.

24. White AA III, Southwick WO, Deponte RJ, Gainor JW, Hardy R: Relief of pain by anterior cervical-spine fusion for spondylosis: A report of sixty-five patients. J Bone Joint Surg Am 55A:525-534, 1973.

25. Woesner ME, Mitts MG: The evaluation of cervical spine motion below $\mathrm{C} 2$ : A comparison of cineroentgenographic and conventional roentgenographic methods. Am J Roentgenol Radium Ther Nucl Med 115:148-154, 1972.

\section{Acknowledgments}

None of the authors received any financial support for preparing this manuscript, nor do they have any commercial interest in the development of the Bryan Cervical Disc Prosthesis. The authors were compensated for conducting the clinical trial.

\section{COMMENTS}

A cervical disc prosthesis that maintains normal cervical motion and alignment after anterior cervical surgery is an ideal device whose time has come. The use of such a device would obviate the need for fusion and prevent abnormal biomechanical stress at the levels adjacent to those fused. If stability were to be maintained, such a device could also prevent the development of neck pain that may occur in patients who have anterior cervical decompression without fusion. Having said that, it should be emphasized that the results that Goffin et al. report are very preliminary. Degenerative disease of the cervical spine is a chronic condition, and although the results after 1 year are very encouraging, this prosthesis must function for decades. If it does function, it will be interesting to see whether patients develop further spondylosis at the motion segment where the device is implanted. Although the patients' outcomes in terms of myelopathy and radiculopathy are excellent, these results are a function of the adequacy of neural decompression and are independent of the use of the device. If neck pain does not occur in the long term and this or a similar device can maintain function in the patient without new or otherwise unanticipated problems, we may be entering a new era of cervical surgery.

\section{Paul R. Cooper New York, New York}

G offin et al. clearly and concisely provide the first report of a large clinical series of patients who had a cervical artificial disc placed after discectomy. This multi-institutional study represents the first documentation of a well-done land- 


\section{Goffin et AL.}

mark clinical study of the first clinically viable cervical spine motion preservation technique. The prior first documentation of surgical attempts at motion preservation provided information that was not clinically useful. Goffin et al. have provided the first glimpse of the true potential of the application of artificial disc technology in the cervical spine. This article is indeed a landmark publication. Without question, the entire spine surgery community will eagerly anticipate the publication of the follow-up article to this preliminary report.

\section{Edward C. Benzel Cleveland, Ohio}

G offin et al. present an excellent preliminary study of a cervical disc prosthesis. Although promising and enticing, their results should be examined carefully. With 60 patients examined at the 6-month follow-up and 30 patients at the 1-year follow-up, the early clinical and radiographic results in several parameters are very good. The authors assessed clinical as well as radiographic outcomes, with the noted caveat of short-term follow-up. The concept of disc replacement remains enigmatic. Why replace a disc when the current treatment options in degenerative disc disease are highly successful with low mobility? In current practice, how often are disc degeneration and/or herniation adjacent to a previous fusion actually encountered? If such a patient is noted, is the adjacent disc degeneration secondary to increased biomechanical forces or merely the natural expectation of already present cervical spondylotic disease? We must be careful not to let advancing technology cloud our thinking.

The literature seems to suggest that fusion accelerates adjacent-level disease, although this hypothesis remains unproved. It seems clear that patients with multilevel fusion experience a higher rate of adjacent disc degeneration, probably secondary to genetic, physiological, and biomechanical factors. Less clear is the incidence of disc degeneration adjacent to a single-level fusion.

Do we really have a problem worth treating? I think so. It makes sense to maintain normal motion within a joint, but at what cost? These questions must be addressed with an open mind and sound scientific methods. Although this study offers no clear answer, it represents an exceptional start toward addressing this vital issue. Cervical arthroplasty must be examined thoughtfully and meticulously and requires long-term follow-up (as the main author, Dr. Goffin, notes), with historical cohorts treated in a more traditional manner. What remains elusive is the discovery of the appropriate materials for arthroplasty. One need look no further than the evolution of hip and knee arthroplasty to discover that sometimes simpler is better. Arthroplasty is possibly superior to arthrodesis in the cervical spine. Only by performing and publishing studies such as this one can neurosurgeons be expected to gain such knowledge.

Regis W. Haid, Jr. Atlanta, Georgia
The authors reported 60 patients who underwent discectomy and implantation of the Bryan Cervical Disc Prosthesis (Spinal Dynamics Corp., Mercer Island, WA), 30 of whom were followed for 12 months. Only 24 of these 30 patients were available for radiographic follow-up at the 12-month examination. This article introduces a new cervical disc prosthesis. Preliminary surgical, functional, and radiographic outcomes seem to be good. Theoretically, the use of prosthetic discs preserves the normal range of motion in the interspace and prevents adjacent-level disease. As the authors state, however, accelerated degeneration at adjacent disc levels after fusion caused by increased stress has only been postulated; it has not been documented. Whether this entity is real or whether adjacent level disease reflects the natural disease process is controversial. Notwithstanding this controversy, the possibility of preserving the normal range of motion at the interspace after discectomy rather than fusing the interspace is attractive. The authors have achieved good short-term outcomes, and I look forward to further reports that describe longer follow-up.

Volker K.H. Sonntag Phoenix, Arizona

$T^{\mathrm{H}}$ his article describes the authors' early experience with the Bryan Cervical Disc Prosthesis in a prospective series. Their preliminary results seem promising in that there did not appear to be any significant device-related complications and motion was preserved at the replaced disc level in most patients who had reached the 1-year follow-up examination. Although cervical disc replacement represents a potentially exciting technology, caution is warranted in interpreting and extrapolating information from these preliminary results. As the authors importantly note, the long-term mechanical and functional durability of this implant remains to be determined, as does its effect on adjacent disc segments.

It is also important to analyze the authors' reported clinical results carefully. The overall reported success rate of $85 \%$ in this series should be qualified by the following observations. First, although the authors note that 97 patients have undergone implantation with the Bryan Cervical Disc Prosthesis, clinical outcome data are available for only 60 patients, and only 30 patients have reached the 1-year postoperative end point. Second, the authors considered even fair outcomes to be clinical successes. Many surgeons consider only excellent and good outcomes to represent clinical success. Third, the authors' determination of outcome may be overly simplified relative to the amount of clinical data collected. An excellent, good, fair, or poor outcome in this series, for example, was determined on the basis of how many outcome measures demonstrated improvement but not by how much each measure improved. In other words, the magnitude of clinical benefit (i.e., effect size) was not considered in the determination of outcome. Improvement in neck pain and/or arm pain from excruciating to severe, for example, could be consistent with an excellent outcome on the basis of the authors' outcome determination methodology.

The authors' comparative analysis with other surgical treatments is also problematic. Comparisons with historical cohorts 
from previously published surgical series are rarely valid, because clinical outcomes are associated not only with each surgical procedure under study but also with the individual surgeon's selection criteria, technical competence, and methods of determining outcome (e.g., what, when, how data are collected and interpreted). Patient factors (e.g., clinical, functional, psychosocial, cultural) that repeatedly have been demonstrated to influence treatment outcomes independently of the surgical procedure may also vary between temporally and geographically distinct populations. Only a prospective, randomized trial that includes both procedures in separate treatment arms can be controlled to eliminate such confounding variables and sources of bias.

Paul C. McCormick New York, New York

$\mathbf{G}_{\mathrm{a}}^{\mathrm{o}}$ offin et al. present preliminary data that they gathered in a prospective cohort of patients who underwent implantation with the Bryan Cervical Disc Prosthesis. Although the details regarding 60 patients are provided, only 30 patients have been followed for 1 year after surgery. This multicenter effort tracked a number of outcome measures in patients who underwent implantation with this device for symptomatic single-level disc disease. The data are compared with those of two other trials: a cost analysis of anterior decompression and stabilization (1) and a prospective randomized trial in which the BAK cage (Sulzer Spine-Tech/Sulzer Medica, Ltd., Minneapolis, MN) was compared with standard fusion (4).

Patient-derived outcomes were determined with the use of the Cervical Spine Research Society and SF-36 instruments. The physical examinations were performed by the surgeon, which could have biased the data. The results were scored with the use of modified Odom's criteria. An independent radiologist performed radiological assessment. Operative time and length of hospital stay were examined. The cost, length of surgery, and clinical outcomes in this small group were similar to those in patients reported in the chosen reference studies. These comparisons are not statistically sound, given the numerous limitations of the experimental design of this project. It is true, however, that the patients whom Goffin et al. describe seem to have benefited greatly from the operative intervention. This is not surprising, given that this patient population generally does well initially with any of a multitude of surgical strategies. All patients main- tained motion at the treated segment, and this motion was similar to preoperative motion in almost $90 \%$ of the group. There were no device failures.

The true test of the success of spinal surgery is the long-term relief of symptoms. This is particularly important for arthroplasty. The rate of development of symptomatic adjacent level disease is about 3\%/yr $(5,6)$. DiAngelo et al. (3) demonstrated that arthrodesis increases local motion in adjacent segments as well as their contribution to global cervical motion. This is probably a significant factor in the acceleration of adjacentlevel disc degeneration. Wigfield et al. (7) reported that adjacent-level motion increases by $15 \% 1$ year after arthrodesis. Patients who underwent implantation with the Bristol (Cummins) cervical disc prosthesis did not exhibit increased motion at the segments adjacent to the surgical level $(2,7)$. I predict that the patients who received the Bryan Cervical Disc Prosthesis will enjoy a similar adjacent-level effect.

This preliminary report of a small patient group contains some bias and lacks statistical rigor. Nevertheless, I think that it represents an important and laudatory effort to improve the overall outcomes of patients with symptomatic cervical disc disease. I anxiously await the authors' report of the long-term results.

Vincent C. Traynelis Iowa City, Iowa

1. Castro FP Jr, Holt RT, Majd M, Whitecloud TS III: A cost analysis of two anterior cervical fusion procedures. J Spinal Disord 13:511-514, 2000.

2. Cummins BH, Robertson JT, Gill SS: Surgical experience with an implanted artificial cervical joint. J Neurosurg 88:943-948, 1998.

3. DiAngelo DJ, Foley KT, Vossel KA, Rampersaud YR, Jansen TH: Anterior cervical plating reverses load transfer through multilevel strut-grafts. Spine 25:783-795, 2000

4. Hacker RJ, Cauthen JC, Gilbert TJ, Griffith SL: A prospective randomized multicenter clinical evaluation of an anterior cervical fusion cage. Spine 25:2646-2655, 2000

5. Hilibrand AS, Carlson GD, Palumbo MA, Jones PK, Bohlman HH: Radiculopathy and myelopathy at segments adjacent to the site of a previous anterior cervical arthrodesis. J Bone Joint Surg Am 81A:519-528, 1999.

6. Hilibrand AS, Yoo JU, Carlson GD, Bohlman HH: The success of anterior cervical arthrodesis adjacent to a previous fusion. Spine 22:1574-1579, 1997.

7. Wigfield C, Gill S, Nelson R, Langdon I, Metcalf N, Robertson J: Influence of an artificial cervical joint compared with fusion on adjacent-level motion in the treatment of degenerative cervical disc disease. J Neurosurg 96[1 Suppl]: 17-21, 2002.

\title{
Contacting Neurosurgery
}

To reach the Editorial Office, please use the following information.

\author{
NEUROSURGERY \\ Michael L.J. Apuzzo, Editor \\ 1975 Zonal Avenue, KAM 415 \\ Los Angeles, CA 90033 \\ Phone: 323/442-3001 \\ Fax: 323/442-3002 \\ Email: neurosurgery-journal@hsc.usc.edu
}

